\title{
STAGES OF CHANGES, BREAST SELF-EXAMINATION PRACTICE AND RELATED HEALTH BELIEFS IN WOMEN- A THEORY-BASED STUDY
}

\author{
Hossein Ashtarian', Marzieh Rohani-Rasaf², Atefeh Afshari ${ }^{3}$, Arman Latifi ${ }^{4}$, Abbas Aghaei ${ }^{5}$, Hadi Darvishi', Mohahmmad-Reza Yousefi ${ }^{7}$, \\ Mehdi Khezeli ${ }^{8}$
}

\author{
${ }^{1}$ Associate Professor, Department of Health Education and Health Promotion, School of Health, Kermanshah University of Medical \\ Sciences, Kermanshah, Iran. \\ 2PhD Candidate, Student Research Committee, Department of Epidemiology, School of Public Health, Shahid Beheshti University of \\ Medical Sciences, Tehran, Iran. \\ ${ }^{3} \mathrm{PhD}$, Faculty of Nursing and Midwifery, Isfahan University of Medical Sciences, Isfahan, Iran. \\ ${ }^{4}$ Assistant Professor, Department of Public Health, Maragheh University of Medical Sciences, Maragheh, Iran. \\ 5PhD Candidate, Clinical Research Development Center, Imam Khomeini Hospital, Kermanshah University of Medical Sciences, \\ Kermanshah, Iran. \\ ${ }^{6} \mathrm{MSc}$, Health Network of Gilan-e Gharb, Kermanshah University of Medical Sciences, Kermanshah, Iran. \\ ${ }_{7}^{7}$ MSc, Health Network of Gilan-e Gharb, Kermanshah University of Medical Sciences, Kermanshah, Iran. \\ ${ }^{8} \mathrm{PhD}$, Research Center for Environmental Determinants of Health, Kermanshah University of Medical Sciences, Kermanshah, Iran.
}

ABSTRACT

\section{BACKGROUND}

Breast self-examination is an important, inexpensive and easy method to detect breast cancer and is recommended monthly for women who are twenty years old and above. This study aimed to investigate the stages of changes, breast self-examination practice and related beliefs in women of Gilan-e Gharb city.

\section{MATERIALS AND METHODS}

The present study was conducted with the participation of 299 literate women of Gilan-e Gharb city in 2015. The data were collected using a questionnaire including demographics, health beliefs and stages of behaviour change and questions related to the breast self-examination. A ten-step checklist was used to measure the accuracy of breast self-examination. The reliability and validity of the instruments were assessed and verified using appropriate methods. The data were analysed by SPSS 19 using the measure of descriptive statistics, T-test, Chi-square, Pearson correlation coefficient and regression.

\section{RESULTS}

The mean age of participants was $32.9 \pm 6.1$ years. Generally, the distribution of individuals according to the breast self-exam stages was as follows: Pre-contemplation $22.1 \%$, contemplation $25.7 \%$, preparation $22.9 \%$, action $4.3 \%$ and maintenance $25 \%$. People who conducted a regular breast self-examination had higher self-efficacy, perceived susceptibility and accuracy scores $(p<.005)$. Stages of change, self-efficacy and perceived barriers were the most important predictors of breast self-exam in this study (p-value $=.001)$.

\section{CONCLUSION}

The results showed that the majority of the participants do not implement regular breast self-examination and has been placed in passive stages of behaviour change. Stages of change, self-efficacy and perceived barriers were the most important predictors of breast self-exam in this study.

\section{KEY WORDS}

Breast Self-Exam, Health Belief Model, Self-Efficacy, Stages of Change.

HOW TO CITE THIS ARTICLE: Ashtarian H, Rasaf MR, Afshari A, et al. Stages of changes, breast self-examination practice and related health beliefs in women- a theory-based study. J. Evolution Med. Dent. Sci. 2018;7(30):3430-3435, DOI: $10.14260 /$ jemds/2018/773

\section{BACKGROUND}

Breast cancer is one of the common cancers among women in the world and its crude incidence rate has been reported as 17.44 per one hundred thousand women in Iran. ${ }^{1}$ Early diagnosis and effective treatment are very important factors,

'Financial or Other Competing Interest': Dr. Khezeli reports grants from Kermanshah University of Medical Sciences, outside the submitted work.

Submission 30-05-2018, Peer Review 10-07-2018,

Acceptance 16-07-2018, Published 23-07-2018.

Corresponding Author:

Mehdi Khezeli,

Kermanshah University of Medical Sciences,

Kermanshah, Iran.

E-mail: khezelimehdi@yahoo.com

DOI: $10.14260 /$ jemds $/ 2018 / 773$

\section{(c) $($ ) $\$$}

which can reduce the morbidity and mortality associated with breast cancer. ${ }^{2}$ Breast Self-Examination (BSE) is an important, inexpensive and easy method to detect breast cancer that is recommended monthly for women who are twenty years old and above.3,4 The purpose of BSE is that women know their breast anatomy, learn the normal situation, and be able to recognise the changes in their health status. ${ }^{5}$ In order to compare three breast cancer detection methods including breast self-examination, Magnetic Resonance Imaging (MRI) and clinical breast examination, the results of a study showed that among 14 diagnosed cancers, 6 cases were diagnosed through self-examination, 6 cases were detected by MRI and 2 cases were diagnosed with clinical examination. 6 
Despite the perceived risk of breast cancer and efficacy of BSE, women are unwilling to perform BSE to detect any changes in their breast on a regular basis. ${ }^{7}$ Numerous studies have reported the different rates of BSE including $69.3 \%$ in São Paulo, 18.1\% in Nigeria and 19\% in Turkey.8-10 Studies carried out in Iran have reported various rates ranging from 4.5 to $28.7 \% .11-15$

Health Belief Model (HBM) is one of the first models proposed to explain the behaviour change toward healthy behaviors. ${ }^{16}$ This model consists of several constructs including the perceived susceptibility, perceived severity, perceived benefits and barriers and self-efficacy. ${ }^{17}$ According to the HBM if a woman understands that she is susceptible to breast cancer and this disease is serious also measures the benefits and the barriers of doing BSE, she will most likely perform BSE regularly. ${ }^{18}$ Commonly, HBM can be used in combination with other theories and models of health education and health promotion. For example, constructs of Transtheoretical or Stages of Change Model.17 The "stages of change model" has been used as a new intervention plan in promoting BSE behaviour. This model assumes that behaviour change occurs in a five-step spectrum including- 1) Precontemplation stage: woman does not want to perform BSE in the next 6 months, 2) Contemplation stage: in which woman does not perform BSE, but she is going to perform BSE in the next 6 months, 3) Preparation stage: woman does not perform but she is going to do BSE in the next 30 days, 4) Action stage: woman did BSE less than 6 months ago, and 5) Maintenance stage: woman did BSE more than 6 months ago. ${ }^{19}$

Given the increasing incidence rate of the breast cancer in women and also important role of BSE in early detection of breast cancer, it is necessary to be investigated the women's beliefs in order to perform this health behaviour and their readiness to changing behaviour using appropriate models of health education and health promotion. Therefore, the present study was conducted to determine the stages of changes, BSE practice and related beliefs in women of Gilan-e Gharb city in 2015.

\section{MATERIALS AND METHODS}

This cross-sectional study was conducted with the participation of 299 literate women of Gilan-e Gharb city, located in Kermanshah province (the west part of Iran), in the second half of 2015. To select the samples, firstly a list of women aged 18 - 50 years who had a health dossier in healthy center of Gilan-e Gharb city was prepared. Then using the systematic random sampling method, the number of women needed based on the determined sample size was randomly selected from the list. For this purpose we chose a number from 1 to 10 randomly, then the next numbers respectively were randomly selected from the list of health dossiers. After explaining the purpose of research to the participants, they completed questionnaires in about 60 minutes.

The inclusion criteria for the sample selection were: residence in Gilan-e Gharb city, being literate, lack of breast diseases as well as completion of the informed consent form. Exclusion criteria were diagnosis of breast disease during the study, emigration or death and unwilling to continue participation in the study. Data were collected using the questionnaire as well as a checklist, in which the latter one was used to record the behaviour of BSE. The questionnaire included 35 questions in 3 sections including the demographic section $(n=5)$, stages of change for BSE $(n=5)$ (i.e. pre-contemplation, contemplation, preparation, action and maintenance), and HBM including 30 questions consisted of perceived susceptibility $(n=6)$ (about the women's perception for chances of getting breast cancer), perceived severity $(n=6)$ (problems and complications of breast cancer), perceived benefits $(n=6)$ (the benefits resulting from performing BSE), perceived barriers $(n=6)$ (barriers to taking action of BSE) and self-efficacy $(n=6)$ (perceived ability to perform BSE). Data about the accuracy of BSE were collected through observation by an informed midwife and the results were recorded in a coded ten-part checklist for each participant. The content validity of the HBM questionnaire for BSE has been approved in previous studies by a panel of experts. ${ }^{12}$ In addition to measuring internal consistency of questions of health belief model constructs, we used Cronbach's alpha method by which reliability of subscales were calculated as follows: perceived susceptibility $=.81$, perceived severity $=.84$, for perceived benefits $=.75$, perceived barriers $=.70$ and self-efficacy $=.82$. The overall reliability of questions of the HBM questionnaire, based on Cronbach's alpha was 80.3. The validity of the stages of change for BSE subscale was measured using S-CVI by Health Education, Gynaecology and Biostatistics specialists. Finally, the validity of the questionnaire was confirmed with coefficient of .96. A two-week test-retest method was also used for reliability assessment of the questionnaire by which coefficient of .85 was obtained, which is an acceptable level of reliability.

In order to evaluate the face validity of the BSE checklist, it was presented to two obstetricians and three midwives to express freely their opinions about it. At the first stage, opinions were collected and necessary changes were made in the BSE checklist. As a result, the checklist changed to illustrated checklist and the number of items increased from 8 to 10 . Then again revised version was sent to obstetricians and midwives and their previous comments were presented on the first stage. Ultimately, the modified checklist was approved as a tool of collecting data for BSE practice.

To evaluate the inter-rater reliability of the scale, five midwives rated the checklist items separately on one role player's participant. None of the five examiners were aware that the participant only plays a role in this regard. The participant performed the steps of BSE in 5 times for five midwives quite similarly. Average score given to the role player by midwives was 72 , whereas the score of a role playing according to the checklist guideline was 70 . Hence, the inter-rater reliability of the data collection checklist in the multiple measurements (by different examiners) was approved.

In this study, we met the ethical issues such as respect to individual freedom and choice to participate in the study, clarification of study for participants and confidentiality of personal information. Informed consent form was obtained before filling out the questionnaire. Data analysis was performed by SPSS 19 and using descriptive statistics, independent t-tests, Chi-square, Pearson correlation and logistic regression at a 95\% confidence level. Assumption of 
normality of the data was examined and approved by Kolmogorov-Smirnov test.

\section{RESULTS}

Totally, 299 women with a mean age of $32.9 \pm 6.1$ years participated in the study. Based on the results, the distribution of the participants according to BSE stages of change were as follows: 66 participants (22.1\%) in precontemplation stage, 77 participants $(25.7 \%)$ in the contemplation stage, 68 participants $(22.7 \%)$ in the preparation stage, 13 participants (4.4\%) in action stage and finally 75 participants $(25.1 \%)$ were in maintenance stage. Stages of change for BSE based on demographic variables were listed in Table 1 . There were no significant differences in stages of change according to education, history of breast lump and history of breast cancer in first-degree relatives of participants based on Chi-square test. We categorised people in action and maintenance stages (who did the BSE regularly) in one group and participants of pre-contemplation, contemplation and preparation in another group. Data analysis by independent t-test showed that the first group significantly had higher self-efficacy, perceived susceptibility and BSE accuracy scores. There were no significant differences between other constructs including perceived severity, perceived benefits and perceived barriers between the two groups (Table 2).

Table 3 shows the correlation matrix of the study variables. Generally, there were significant correlations between the perceived susceptibility, severity, perceived barriers and self-efficacy as well as stages of change with the scores of BSE. The stages of change and self-efficacy construct had the highest correlation with the score of self-examination $(\mathrm{r}=.847$ and $\mathrm{r}=.639$ respectively, $\mathrm{p}<.001)$ as shown in Table4 , in final model of step-wise regression analysis, after adjusting the age variable, three constructs including the stages of change, perceived barriers and self-efficacy were the most important predictors of the BSE practice respectively in this study ( $\mathrm{p}$-value $=.001$ ).

\begin{tabular}{|c|c|c|c|c|c|c|}
\hline & PC* & C & PR & AC & M & $\begin{array}{c}\text { P- } \\
\text { value }\end{array}$ \\
\hline \multicolumn{7}{|c|}{ Education } \\
\hline Sub-Diploma & \begin{tabular}{|c}
15 \\
$(18.1 \%)$
\end{tabular} & $\begin{array}{c}20 \\
(24.1 \%)\end{array}$ & $\begin{array}{c}15 \\
(18.1 \%)\end{array}$ & $\begin{array}{c}5 \\
(12.0 \%)\end{array}$ & \begin{tabular}{|c|}
23 \\
$(27.7 \%)$
\end{tabular} & \multirow{3}{*}{.087} \\
\hline Diploma & $\begin{array}{c}37 \\
(23.3 \%)\end{array}$ & $\begin{array}{c}44 \\
(27.7 \%)\end{array}$ & $\begin{array}{c}32 \\
(20.1 \%)\end{array}$ & $\begin{array}{c}5 \\
(3.1 \%)\end{array}$ & \begin{tabular}{|c|}
41 \\
$(25.8 \%)$
\end{tabular} & \\
\hline Academic & $\begin{array}{c}14 \\
(22.6 \%)\end{array}$ & $\begin{array}{c}13 \\
(21.0 \%)\end{array}$ & $\begin{array}{c}21 \\
(33.9 \%)\end{array}$ & $\begin{array}{c}3 \\
(4.8 \%)\end{array}$ & \begin{tabular}{|c|}
11 \\
$(17.7 \%)$
\end{tabular} & \\
\hline \multicolumn{7}{|c|}{ History of Breast Lump } \\
\hline Yes & $\begin{array}{c}3 \\
(7.7 \%)\end{array}$ & \begin{tabular}{|c|}
5 \\
$(12.8 \%)$
\end{tabular} & $\begin{array}{c}10 \\
(25.6 \%)\end{array}$ & $\begin{array}{c}3 \\
(7.7 \%)\end{array}$ & $\begin{array}{c}18 \\
(46.1 \%)\end{array}$ & \multirow{2}{*}{199} \\
\hline No & $\begin{array}{c}63 \\
(24.2 \%)\end{array}$ & $\begin{array}{c}72 \\
(29.6 \%)\end{array}$ & $\begin{array}{c}58 \\
(22.4 \%)\end{array}$ & $\begin{array}{c}10 \\
(3.8 \%)\end{array}$ & \begin{tabular}{|c|}
57 \\
$(21.9 \%)$
\end{tabular} & \\
\hline \multicolumn{7}{|c|}{ Family History of Cancer } \\
\hline Yes & $\begin{array}{c}2 \\
(5.7 \%)\end{array}$ & $\begin{array}{c}8 \\
(22.9 \%)\end{array}$ & $\begin{array}{c}10 \\
(28.6 \%)\end{array}$ & $\begin{array}{c}3 \\
(8.6 \%)\end{array}$ & \begin{tabular}{|c|}
12 \\
$(34.3 \%)$
\end{tabular} & \multirow{2}{*}{.060} \\
\hline No & $\begin{array}{c}64 \\
(24.2 \%)\end{array}$ & $\begin{array}{c}69 \\
(26.1 \%)\end{array}$ & $\begin{array}{c}58 \\
(22.0 \%)\end{array}$ & $\begin{array}{c}10 \\
(3.8 \%)\end{array}$ & \begin{tabular}{|c|}
63 \\
$(23.9 \%)$
\end{tabular} & \\
\hline Total & $\begin{array}{c}66 \\
(22.1 \%)\end{array}$ & $\begin{array}{c}77 \\
(25.7 \%)\end{array}$ & $\begin{array}{c}68 \\
(22.7 \%)\end{array}$ & $\begin{array}{c}13 \\
(4.4 \%)\end{array}$ & $\begin{array}{c}75 \\
(25.1 \%)\end{array}$ & \\
\hline & $\begin{array}{l}\text { tages of } \\
\text { based or }\end{array}$ & tang & 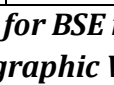 & 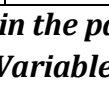 & 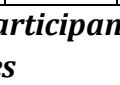 & \\
\hline
\end{tabular}

*PC= Pre-contemplation, $\mathrm{C}=$ Contemplation, $\mathrm{PR}=$ Preparation, $\mathrm{A}=$ Action, $\mathrm{M}=$ Maintenance.

\begin{tabular}{|c|c|c|c|}
\hline $\begin{array}{l}\text { BSE Background } \\
\text { Variables }\end{array}$ & $\begin{array}{c}\text { Have } \\
(n=122) \\
\text { Mean } \pm \text { SD }\end{array}$ & $\begin{array}{c}\text { Do not have } \\
(n=177) \\
\text { Mean } \pm \text { SD }\end{array}$ & $P$ value \\
\hline $\begin{array}{c}\text { Perceived } \\
\text { susceptibility }\end{array}$ & $14.61 \pm 3.84$ & $12.50 \pm 3.99$ & $.005^{*}$ \\
\hline Perceived severity & $18.83 \pm 5.49$ & $20.24 \pm 6.20$ & .207 \\
\hline Perceived benefits & $25.70 \pm 2.75$ & $25.37 \pm 2.24$ & .568 \\
\hline Perceived barriers & $11.27 \pm 3.95$ & $12.58 \pm 3.44$ & .051 \\
\hline Self-efficacy & $23.30 \pm 3.50$ & $16.1 \pm 4.63$ & $.001^{*}$ \\
\hline BSE practice & $69.87 \pm 11.80$ & $20.9 \pm 15.66$ & $.001^{*}$ \\
\hline
\end{tabular}

${ }^{*}$ Differences is significant at the 0.05 level (2-tailed).

\begin{tabular}{|c|c|c|c|c|c|c|c|}
\hline Variables & 1 & 2 & 3 & 4 & 5 & 6 & 7 \\
\hline 1. BSE Practice & 1 & & & & & & \\
\hline $\begin{array}{c}\text { 2. Perceived } \\
\text { susceptibility }\end{array}$ & $.292^{*}$ & 1 & & & & & \\
\hline $\begin{array}{l}\text { 3. Perceived } \\
\text { severity }\end{array}$ & .125 &.$\underline{308}^{*}$ & 1 & & & & \\
\hline $\begin{array}{l}\text { 4. Perceived } \\
\text { benefits }\end{array}$ & .033 & $.351^{*}$ & $.498^{*}$ & 1 & & & \\
\hline $\begin{array}{l}\text { 5. Perceived } \\
\text { barriers }\end{array}$ &.$- .289 *$ & .088 & .150 & .091 & 1 & & \\
\hline 6. Self-efficacy & $.639^{*}$ & $.335^{*}$ & .115 & .024 & $.221^{*}$ & 1 & \\
\hline $\begin{array}{l}\text { 7. Stages of } \\
\text { change }\end{array}$ & $.847^{*}$ & $.243^{*}$ & .127 & .005 & $.237^{*}$ & $.702^{*}$ & 1 \\
\hline
\end{tabular}

${ }^{*}$ Correlation is significant at the 0.01 level (2-tailed).

\begin{tabular}{|c|c|c|c|c|c|}
\hline & \multirow{2}{*}{ Variables } & $\boldsymbol{\beta}$ & $\boldsymbol{\beta}$ (SE) & \multirow{0}{\text{OR}}{} & \multicolumn{2}{|c|}{$\begin{array}{c}\text { 95\% C.I. for } \\
\text { EXP (B) }\end{array}$} \\
\cline { 4 - 6 } & & & & Lower & Upper \\
\hline Stages of change & 2.328 & .421 & 10.254 & 4.494 & 23.399 \\
\hline Self-efficacy & .389 & .139 & 1.475 & 1.122 & 1.938 \\
\hline Perceived barriers & -.158 & .074 & 0.854 & .739 & .987 \\
\hline Table 4. Regression Results for predicting BSE practice in \\
Women \\
\hline
\end{tabular}

\section{DISCUSSION}

In the present study, $40.8 \%$ of participants declared that they have performed breast self-examination irregularly, while $29.5 \%$ reported that they have done BSE regularly. Studies have reported different results in this area. Studies conducted in Iran demonstrated that the overall self-examination action is from $17 \%$ to $32 \%$ and also regular self-examination from $6.5 \%$ to $17 \% \cdot 1,11,20,21$ By comparing these results with the present study, it may be concluded that the rate of BSE in the present study is higher than the other studies. In a study by Janda et al in 2002, 61.6\% of women performed BSE but only $20.1 \%$ of those were done regularly. ${ }^{22}$ Dündar and colleagues have also reported that $29.5 \%$ of women in their study in an irregular basis conducted self-examination and only $10.2 \%$ performed a regular BSE (as monthly). ${ }^{23}$

Based on above-mentioned studies, it can be seen that BSE is measured with two criteria: doing or not doing breast self-examination and regular or irregular breast selfexamination. This type of measurement creates restrictions for researchers, which most notably is neglecting the 
differences between people who are placed in any of the mentioned situations. For example in this categorising individuals who are not doing self-examination are generally defined in one category. This is while those who do not perform self-examination are different in terms of readiness for behaviour change in the future. In this study, we chose stages of change model to assess the current status of BSE in the women and their readiness to change behaviour in the future.

It has been proposed that designing and implementing programs that classify people based on stages of change could be more effective than traditional health education interventions. ${ }^{24} \mathrm{~A}$ key assumption of the stages of change model is that if the educational interventions want to be more effective, they should be planned according to the stages of change. 25 The important feature of the model is that for each of the stages of behaviour change, it is necessary to plan the strategies and specific interventions based on the readiness of individuals to change or adopting behaviours. ${ }^{26}$ In the current study, $25.1 \%$ of patients were located in the maintenance stage and $4.4 \%$ in the action stage for performing BSE. Totally, based on the stages of change $29.5 \%$ of people were doing BSE regularly and $70.7 \%$ were classified as inactive. In this study $21 \%$ were present in the precontemplation stage, which based on the definition of Prochaska these people have been introduced as resistant or unmotivated customers in health programs. ${ }^{27}$ Furthermore, $25.8 \%$ of individuals were in contemplation stage. People in this stage compared to pre-contemplation are aware of the benefits of behaviour change, but they believe that the barriers are more than perceived benefits to change their behaviour. Generally, traditional health education programs cannot be appropriate for the contemplators, because these programs are looking for quick action participants. ${ }^{27}$ Preparation group members, who included $22.9 \%$ of subjects, stated that they intend to conduct BSE behaviour in the next month. These people, besides traditional health education programs are one of the emphasised target groups in transtheoretical based studies, because they are ready to change in the near future and have greater self-efficacy for continuing the behaviour.27,28 One positive aspect in design of educational interventions based on the transtheoretical model is possibility of classifying individuals in different stages of behaviour change, which was previously mentioned. This classification allows the instructor to design and adjust the educational program based on people's readiness for change and for each group consider different and appropriate strategies.

Health belief model is another model that is widely applied in diverse kinds of educational programs for BSE and has a special emphasis on people's health beliefs. In the present study, perceived susceptibility and perceived selfefficacy in the women who performed BSE were significantly more than those who did not do. These results are consistent with the nature of the health belief model. In the previous studies, self-efficacy in people who have performed BSE has been reported more than other group. ${ }^{21,23,29-32}$ Self-efficacy is important, because its level has an impact on people's readiness for change. ${ }^{33}$ In the present study also those who had higher self-efficacy were located mainly in the action and maintenance stages and lower self-efficacy belonged to those who do not perform regular self-examination and were located in passive stages including pre-contemplation, contemplation and preparation. In this study similar to other study, ${ }^{21}$ perceived susceptibility in people who performed regular BSE was more than other group, but in other studies perceived susceptibility between two groups did not show a significant difference.23,29-32

Results showed that stages of change, self-efficacy and perceived barriers were the most important predictors of BSE conducting. Stages of changes construct was the most important predictor for BSE practice. It is proposed that interventions based on the stages of change model, in comparison with other studies are more effective in facilitating behaviour change. ${ }^{34}$

In this study, self-efficacy was identified as the second most important predictor of the BSE. Several studies have been approved the predictive power of this structure in breast self-examination behaviour.23,35-37 For example, in the study of Noroozi and colleagues, self-efficacy has been introduced as the most important variable in predicting BSE that also had an effect on perceived susceptibility, severity, barriers and benefits. ${ }^{37}$

Other significant predictor in this study was perceived barriers. Barriers are associated with therapeutic characteristics and the preventive measures which may be uncomfortable, expensive, inconvenient and painful. Both retrospective and prospective studies have shown that perceived barriers is one of the most powerful components for predicting protective health behaviours. ${ }^{17}$ In the similar studies also, perceived barriers after self-efficacy or confidence ranked as the highest predictive element for BSE behaviour. ${ }^{32,35}$ In this study, we compared the mean scores of the barrier questions and concluded that psychological factors such as modesty, unpleasant feeling and stress of finding mass were the main problems in this field. In the same studies based on regression analysis, results were similar to this study and between the health belief model constructs only perceived self-efficacy and perceived barriers had a predictive role for BSE prediction. ${ }^{31,32}$

In this study, a questionnaire was used to collect some of the data. Due to the nature of the questionnaire based studies, there is a probability of under-reporting or overreporting. In this study to increase the validity of the data, an illustrated checklist was used to collect data on the accuracy of breast self-examination which is one of the strengths of the study. Another strengths of this study was to combine health education and health promotion models to evaluate the behaviour and effective factors of breast self-examination.

\section{CONCLUSION}

The results showed that the majority of the participants do not implement regular breast self-examination and has been placed in passive stages of behaviour change. Stages of change, self-efficacy and perceived barriers were the most important predictors of breast self-exam in this study. We suggest for more effective educational intervention for the promotion of breast self-examination, researchers and practitioners in health systems should have special attention to the stages of change, self-efficacy and perceived barriers. Also, considering the stages of change as the most important predictor was placed alongside the structures of HBM, we conclude that this structure can be used as a complementary 
structure in interventions based on HBM for promoting breast self-examination. This can lead to increased targeted training and relevancy between educations with the individual's readiness to change behaviour.

\section{Abbreviations}

BSE: Breast Self-Exam; MRI: Magnetic Resonance Imaging; HBM: Health Belief Model.

\section{ACKNOWLEDGEMENTS}

The authors would like to thank the Kermanshah University of Medical Sciences for providing financial support for this project (No. 91148)

\section{REFERENCES}

[1] Montazeri A, Vahdaninia M, Harirchi I, et al. Breast cancer in Iran: need for greater women awareness of warning signs and effective screening methods. Asia Pac Fam Med 2008;7(1):6.

[2] Avci IA. Factors associated with breast selfexamination practices and beliefs in female workers at a Muslim community. Eur J Oncol Nurs 2008;12(2):127-33.

[3] Avci IA, Ozcan A, Altay B, et al. The problems encountered by midwives during Breast selfexamination training. Eur J Oncol Nurs 2008;12(4):329-33.

[4] Seif NY, Aziz MA. Effect of Breast self-examination training program on knowledge, attitude and practice of group working women. J of the Egyptian Nat Cancer Inst 2000;12(2):105-15.

[5] Khatib OMN, Modjtabai A. Guidelines for the early detection and screening of breast cancer: EMRO Technical Publications Series: 30. WHO Regional Office for the Eastern Mediterranean 2006.

[6] Wilke LG, Broadwater G, Rabiner S, et al. Breast selfexamination: defining a cohort still in need. Am J Surg 2009;198(4):575-9.

[7] Friedman LC, Nelson DV, Webb JA, et al. Dispositional optimism, self-efficacy and health beliefs as predictors of breast self-examination. Am J Prev Med 1994;10(3):130-5.

[8] Carelli I, Pompei LM, Mattos CS, et al. Knowledge, attitude and practice of breast self-examination in a female population of metropolitan Sa o Paulo. The Breast 2008;17(3):270-4.

[9] Balogun MO, Owoaje ET. Knowledge and practice of breast self-examination among female traders in Ibadan, Nigeria. Ann Ib Postgrad Med 2005;3(2)52-6.

[10] Özturk M, Engin VS, Kisioglu AN. The practice of breast-self-examination among women at Gulistan district of Isparta. East J Med 1999;4(2):47-50.

[11] Farshbaf-Khalili A, Shahnazi M, Ghahvehchi A, et al. Performance conditions of breast cancer screening methods and its efficient factors among women referring to health centers of Tabriz. Iran J Nurs Res 2009;4(12 \& 13):27-38.

[12] Karimy M, Hasani M, Khoram R, et al. The effect of education based on health belief model on breast selfexamination in health liaisons of Zarandieh City. Zahedan J Res Med Sci 2008;10(4):283-91.
[13] Mahouri KH, Sadeghi-Hassanabadi A, Talei AR. Women's knowledge and practice about different screening methods of breast cancer referring to Shiraz health centers, Iran. Med J Hormozgan University 2003;7(2):68-74.

[14] Godazandeh GHA, Khani H, Khalilian AR, et al. Knowledge and practice of above 15 years old females towards breast cancer prevention in Sari Township, 2004. J Mazand Univ Med Sci 2006;16(52):64-76.

[15] Banaeian S, Kazemian A, Kheiri S. Knowledge, attitude and practice about breast cancer screening and related factors among women referred to health care centers in Boroujen in 2005. J Shahrekord Univ Med Sci 2006;7(4):28-34.

[16] Schiavo R. Health communication: from theory to practice. United States of America: Jossey-Bass 2007: p. 37-8.

[17] Champion VL, Skinner SC. Health belief model. In: Glanz K, Rimer KB, Viswanath K, eds. Health behavior and health education: theory, research and practice. $4^{\text {th }}$ edn. USA: Jossey-Bass 2008: p. 46-60.

[18] Champion VL. Instrument refinement for breast cancer screening behaviors. Nurs Res 1993;42(3):139-43.

[19] Ghahremani L, Mousavi Z, Kaveh MH, et al. Self-care education programs based on a trans-theoretical model in women referring to health centers: breast self-examination behavior in Iran. Asian Pac J Cancer Prev 2016;17(12):5133-8.

[20] Yavari P, Mehrabi Y, Poor-Hoseingholi MA. Knowledge and practice of women toward breast selfexamination: a case-control study. J Ardabil Univ Med Sci 2004;5(4):371-7.

[21] Mahmood A, Ramazani AA. Study of knowledge, attitude and practice of presenting women to Zabol health centers with regard to breast self-examination by using health belief model in 2009. Modern Care J 2011;8(2):65-72.

[22] Janda M, Stanek C, Newman B, et al. Impact of videotaped information on frequency and confidence of breast self-examination. Breast Cancer Res Treat 2002;73(1):37-43.

[23] Dündar PE, Özmen D, Öztürk B, et al. The knowledge and attitudes of breast self-examination and mammography in a group of women in a rural area in western Turkey. BMC Cancer 2006;6:43.

[24] DiClemente RJ, Crosby RA, Kegler MC. Emerging theories in health promotion practice and research: strategies for improving public health. San Francisco, CA: Jossy-Bass 2002: p. 1-2.

[25] Wilson GT, Schlam TR. Transtheoretical model and motivational interviewing in the treatment of eating and weight disorders. Clin Psychol Rev 2004;24(3):361-78.

[26] Lach HW, Everard KM, Highsein G, et al. Application of the transtheoretical model to health education for older adults. Health Promot Pract 2004;5(1):88-93.

[27] Prochaska JO, Redding CA, Evers KE. The transtheoretical model and stages of change. In: Glanz $\mathrm{K}$, Rimer KB, Viswanath K, eds. Health behavior and health education: theory, research and practice. $4^{\text {th }}$ edn. San Francisco, USA: Jossey-Bass 2008: p. 97-122. 
[28] Prochaska JO, Johnson S, Lee P. The transtheoretical model of behavior change. In: Shumaker SA, Ockene JK, Riekert KA, eds. The handbook of health behavior change. $3^{\text {rd }}$ edn. New York: Springer 2009.

[29] Canbulat N, Uzun O. Health beliefs and breast cancer screening behaviors among female health workers in Turkey. Eur J Oncol Nurs 2008;12(2):148-56.

[30] Norman P, Brain K. An application of an extended health belief model to the prediction of breast selfexamination among women with a family history of breast cancer. Br J Health Psychol 2005;10(Pt 1):1-16.

[31] Erblich J, Bovbjerg DH, Valdimarsdottir HB. Psychological distress, health beliefs and frequency of breast self-examination. J Behav Med 2000;23(3):27792.

[32] Sadat-Tavafian S, Hasani L, Aghamolaei T, et al. Prediction of breast self-examination in a sample of Iranian women: an application of the Health Belief Model. BMC Women's Health 2009;9:37.
[33] Jolicoeur D, Ewy BM, Ockene JK, et al. Addressing tobacco use and dependence. In: Shumaker SA, Ockene JK, Riekert KA, eds. The handbook of health behavior change. $3^{\text {rd }}$ edn. New York: Springer 2009.

[34] Kreuter MW, Skinner CS. Tailoring: What is in a name? Health Educ Res 2000;15(1):1-4.

[35] Karimy M, Niknami SH, Amin-Shokravi F, et al. The relationship of breast self-examination with selfesteem and perceived benefits/barriers of selfefficacy in health volunteers of Zarandieh city. Iran J Breast Dis 2009;2(25):41-8.

[36] Jirojwong S, MacLennan R. Health beliefs, perceived self-efficacy and breast self-examination among Thai migrants in Brisbane. J Adv Nurs 2003;41(3):241-9.

[37] Noroozi A, Jomand T, Tahmasebi R. Determinants of breast self-examination performance among Iranian women: an application of the health belief model. J Canc Educ 2011;26(2):365-74. 